\title{
Measurement of Bilirubin-Albumin Binding. I. Comparative Analysis of Four Methods and Four Human Serum Albumin Preparations
}

\author{
KWANG-SUN LEE, ${ }^{(31)}$ LAWRENCE M. GARTNER, AND SERGIO L. VAISMAN \\ Department of Pediatrics, The Rose F. Kennedy Center for Research in Mental Retardation and the Liver \\ Research Center of the Albert Einstein College of Medicine, Bronx, New York, USA
}

\section{Summary}

Four methods for the measurement of bilirubin-albumin binding have been compared. Three of these, the fluorescent dye binding (Direct Yellow 7), Sephadex G-25 column chromatography, and the 2-(4-hydroxyazobenzene)benzoic acid (HBABA) dye binding methods demonstrate significant correlations of measured binding capacities for bilirubin over a range of bilirubin/albumin molar ratios. All three methods concurred in the demonstration that fresh adult human sera had a higher molar albumin binding capacity for bilirubin than the pruified human serum albumin preparations. The fluorescent dye binding and Sephadex column methods agreed most closely in defining presumed deficiency in binding capacity. The HBABA dye binding method was less consistent and appeared to measure non-bilirubin binding sites on albumin in addition to bilirubin binding sites. The fourth method, the saturation index, yielded highly variable results as compared with the other methods because of an inherent excessive risk of laboratory error.

\section{Speculation}

The four methods studied measure different aspects of bilirubin-albumin binding. Before clinical use, these methods may further require a systematic comparison utilizing sera from newborn infants. The effect of various pathophysiologic states and gestational age on the results of binding measured with these methods should be assessed. Neurobehavioral outcome of these infants in relation to the measured reserve binding capacity with these methods may establish clinical usefulness of any one or all of these methods.

Unconjugated bilirubin is transported mainly bound to serum albumin $(13,21)$. When the unconjugated bilirubin concentration exceeds albumin binding capacity, the unbound fraction is believed to be transferred into the central nervous system, resulting in kernicterus (3).

In order to evaluate the role of bilirubin binding to serum albumin as a risk factor in kernicterus, various methods have been developed $(7,9,12,14,15,17,19,25)$. These methods measure either reserve albumin binding capacity for bilirubin or the presence of free and/or loosely bound bilirubin. Among them, three methods, HBABA dye binding (19), Sephadex G25 gel column chromatography (11), and saturation index (SI) method (17), have been more widely utilized. Only a few reports have associated "defective binding" with an increased risk for kernicterus $(11,18,24)$. Each of the methods is posited on a different theoretic concept and may measure a quite different aspect of albumin binding of bilirubin. Uncertainty regarding interpretation of binding results has prevented their widespread clinical use. Serum bilirubin concentrations continue to be the major indicators for exchange transfusion or phototherapy in the prevention of kernicterus.

This communication systematically explores the concurrences and differences in four methods applied to the measurement of albumin binding of bilirubin using identical artificially jaundiced adult human serum and purified human serum albumin (HSA) standards. The four methods used are; 1) Sephadex G-25 column chromatography, 2) fluorescent dye (Direct Yellow 7) binding, 3) HBABA dye binding, and 4) SI.

\section{MATERIALS AND METHODS}

Crystalline HSA was purchased from Sigma Chemical Co. (preparation A), and Miles Laboratories, Inc. (preparation B); fluid HSA (5\%) (Buminate) was obtained from Travenol Laboratories, Inc. (preparation C). Fresh adult human serum was obtained from four healthy adult male subjects (preparation D). Bilirubin was purchased from Eastman Organic Chemicals and give a molar extinction coefficient $\left(E_{453}^{1 \mathrm{M} .1 \mathrm{~cm}}\right)$ in chloroform of $5.95 \times 10^{4}$ and was used without further purification.

Bilirubin $(2.5$ to $70.0 \mathrm{mg} / \mathrm{dl})$ in $\mathrm{HSA}$ at $\mathrm{pH} 7.4$ was prepared in the dark and in ice by addition of a concentrated solution of bilirubin in $0.1 \mathrm{~N} \mathrm{NaOH}$ to each albumin preparation and to fresh serum. HSA solutions $(4 \mathrm{~g} / \mathrm{dl})$ were prepared in $0.1 \mathrm{M}$ phosphate buffer, $\mathrm{pH}$ 7.4. The final $\mathrm{pH}$ of all bilirubin-albumin preparations was 7.4 and was adjusted as necessary with a glasselectrode $\mathrm{pH}$ meter (Corning).

Four completely separate sets of bilirubin-albumin samples were prepared for each type of albumin (preparations A, B, C, and D) and the result for each point is the mean of the four independent determinations. Measurements were performed simultaneously with each of the four methods on the same sample. Thus, for each bilirubin concentration at total of 64 determinations of binding were performed.

SEPHADEX G-25 COLUMN CHROMATOGRAPHY

This method was utilized as described by Kapitulnik et al. (11). The column $(6.5 \times 0.6 \mathrm{~cm})$ was filled with $2 \mathrm{ml}$ Sephadex G-25 fine (Pharmacia) and equilibrated with phosphate buffer $(0.1 \mathrm{M}, \mathrm{pH} 7.4)$. A sample, $0.1 \mathrm{ml}$, was mixed with $0.75 \mathrm{ml}$ buffer and placed on the column, followed by $2 \mathrm{ml}$ buffer. A solution prepared by dissolving 1 diazo tablet (Ictotest tablet, Ames Co.) in $0.75 \mathrm{ml}$ distilled water was then placed on the column. Bilirubin remaining on the column reacted with the diazo solution to give a blue or purple band. The intensity of the band was assessed after all diazo reagent had entered the gel bed. Staining was graded as follows; negative = no blue band; $\pm=$ questionable blue color band; $F=$ obvious but faint blue 
color band; $+=$ definite clear blue or purple band. The latter two, $\mathrm{F}$ and + , were interpreted as positive results.

\section{FLUORESCENT DYE (DIRECT YELLOW 7) BINDING}

This method was used as reported previously by Lee $e t$ al. (15). Three microliters of specimen were added to $10 \mathrm{ml} 0.1 \mathrm{M}$ phosphate buffer, pH 7.4, containing $0.35 \mathrm{mg} / \mathrm{dl}$ Direct Yellow 7 (DY7). The blank was the dye-buffer solution alone. Readings were performed on a filter fluorometer (Coleman Jr., model C12 , primary filter $12-221$, secondary filter 14-211) calibrated with quinine sulfate solutions in sulfuric acid (zero point set with $0.15 \mathrm{mg}$ quinine sulfate $/ \mathrm{dl}$ and 100 point with $0.3 \mathrm{mg} / \mathrm{dl}$ ). The net difference between blank and sample readings was designated as "enhanced fluorescence" $(\Delta \mathrm{F})$.

\section{HBABA DYE BINDING}

This method was used as originally reported by Porter and Waters (19). The dye bland solution consisted of $0.1 \mathrm{ml}$ water and $3.0 \mathrm{ml}$ HBABA dye solutin $\left(3 \times 10^{-4} \mathrm{M}\right)$. The sample blank solution consisted of $0.1 \mathrm{ml}$ sample and $3.0 \mathrm{ml}$ buffer $(0.02 \mathrm{M}$ Tris $)$. The test solution consisted of $0.1 \mathrm{ml}$ sample and $3.0 \mathrm{ml}$ HBABA dye solution $\left(3 \times 10^{-4} \mathrm{M}\right)$. Optical density (OD) of each was read at $510 \mathrm{~nm}$, using distilled water as an instrument blank on the spectrophotometer (Gilford, model $300-N$ ). The net OD of a test sample (test OD minus both dye and sample blank OD) was expressed as percentage of the net OD of $4 \mathrm{~g} / \mathrm{dl}$ crystalline HSA (Sigma).

\section{SATURATION INDEX (SI)}

This method was utilized as reported by Odell et al. (17); 50 $\mu l$ sample were transferred with a micropipette (Drummond Scientific Co.) into two quartz cuvettes (10 mm light-path) each containing $2.5 \mathrm{ml} 0.1 \mathrm{M}$ phosphate buffer, $\mathrm{pH} 7.4$. To the control cuvette, an additional $150 \mu \mathrm{l}$ buffer were added; $150 \mu \mathrm{l}$ $25 \mu \mathrm{M}$ sodium salicylate were added to the other cuvette. The cuvette samples were mixed by inversion and immediately placed in a recording double beam spectrophotometer (HitachiPerkin-Elmer). OD values measured from $600 \mathrm{~nm}$ to $400 \mathrm{~nm}$ against phosphate buffer, $0.1 \mathrm{M}, \mathrm{pH} 7.4$. The difference in OD at $460 \mathrm{~nm}$ between the two cuvettes was expressed as a percentage of change of the test cuvette as compared with the control. Additional SI measurements were performed to establish reproducibility of the method. Bilirubin at concentrations from $2.5-17.5 \mathrm{mg} / \mathrm{dl}$ (in $2.5 \mathrm{mg} / \mathrm{dl}$ increments) and from $20-70$ $\mathrm{mg} / \mathrm{dl}$ (in $10 \mathrm{mg} / \mathrm{dl}$ increments) was prepared in HSA (Miles Lab.) (4 g/dl 0.1 M phosphate buffer, pH 7.4). The SI procedure was performed on each sample six times sequentially within a period of $1 \mathrm{hr}$.

Albumin concentrations were determined by the bromcresol green method (4). Bilirubin concentrations were measured by the Jendrassik and Grof method (8). The data are expressed as mean \pm 1 SD and were analyzed with Student's $t$-test, analysis of variance, and linear correlation as appropriate (6).

\section{RESULTS}

All three purified HSA were dissolved to a concentration of $4.0 \mathrm{~g} / \mathrm{dl}$. The mean albumin concentration for fresh adult human sera was $4.4 \pm 0.2(\mathrm{SD})$. The data for fresh adult human sera has been adjusted to that of $4.0 \mathrm{~g} / \mathrm{dl}$. Total serum bilirubin concentrations of all four adult human sera were less than 0.8 $\mathrm{mg} / \mathrm{dl}$.

\section{SEPHADEX G-25 COLUMN CHROMATOGRAPHY}

This method demonstrated bilirubin adsorption to the gel bed with all four albumin preparations with increasing bilirubin concentrations as shown on Table 1. Significant adsorption of bilirubin to the gel $(\mathrm{F}$ or + ) was first observed with crystalline HSA preparation A at a B:A MR of 0.75 with crystalline HSA preparation $B$ at 0.90 , with liquid HSA preparation $C$ at 1.05 and with adult human sera (D) at 1.09 (Table 1).

\section{FLUORESCENT DYE (DY7) BINDING}

This method demonstrated progressive inhibition of "enhancement of fluorescence" $(\Delta F)$ with increasing concentrations of bilirubin, in all four HSA preparations (A, B, C, and D) (Fig. 1). The initial $\Delta F$ value before addition of bilirubin was highest in whole sera (D) $40.3 \pm 2.5$ (SD) and lowest in crystalline HSA preparations $(A$ and $B), 24.8 \pm 2.1(\mathrm{SD})$ and $23.5 \pm 1.4$ (SD), respectively (Fig. 1). In the three purified HSA preparations, complete inhibition of mean $\Delta F$ occurred at bilirubin/ albumin molar ratios (B:A MR) between 1.0 and 1.2 (bilirubin

Table 1. Bilirubin binding capacities of three human serum albumin preparations and adult human sera measured with Sephadex G-25 gel column chromatographic method (13) ${ }^{1}$

\begin{tabular}{|c|c|c|c|c|c|c|c|c|c|}
\hline \multirow[b]{2}{*}{ Albumin preparation } & \multirow[b]{2}{*}{ Sample no. } & \multicolumn{8}{|c|}{ Bilirubin/albumin molar ratio } \\
\hline & & 0.45 & 0.60 & 0.75 & 0.90 & 1.05 & 1.20 & 1.35 & 1.50 \\
\hline \multirow[t]{4}{*}{ Sigma crystalline (A) } & 1 & - & - & \pm & $\mathbf{F}$ & + & + & + & + \\
\hline & 2 & - & - & \pm & $\mathbf{F}$ & + & + & + & + \\
\hline & 3 & - & - & - & \pm & + & + & + & + \\
\hline & 4 & - & - & \pm & $\mathrm{F}$ & + & + & + & + \\
\hline \multirow[t]{4}{*}{ Miles Lab. crystalline (B) } & 1 & - & \pm & $\mathbf{F}$ & + & + & + & + & + \\
\hline & 2 & - & - & \pm & $\mathbf{F}$ & + & + & + & + \\
\hline & 3 & - & \pm & $\mathbf{F}$ & + & + & + & + & + \\
\hline & 4 & - & \pm & $\mathbf{F}$ & + & + & + & + & + \\
\hline \multirow{6}{*}{ Hyland liquid (C) } & 1 & - & - & - & - & \pm & + & + & + \\
\hline & 2 & - & - & - & $\mathbf{F}$ & + & + & + & + \\
\hline & 3 & - & - & - & \pm & $\mathbf{F}$ & + & + & + \\
\hline & 4 & - & - & - & \pm & + & + & + & + \\
\hline & & \multicolumn{8}{|c|}{ Bilirubin/albumin molar ratio } \\
\hline & & 0.41 & 0.55 & 0.68 & 0.82 & 0.95 & 1.09 & 1.23 & 1.36 \\
\hline \multirow[t]{4}{*}{ Fresh adult human serum (D) } & 1 & - & - & - & - & - & \pm & $\mathbf{F}$ & + \\
\hline & 2 & - & - & - & - & \pm & $\mathrm{F}$ & + & + \\
\hline & 3 & - & - & - & - & \pm & $\mathrm{F}$ & + & + \\
\hline & 4 & - & - & - & - & \pm & $\mathrm{F}$ & + & + \\
\hline
\end{tabular}

\footnotetext{
1 -: no blue band; \pm : uncertain; F: faint blue band; +: definite clear blue or purple band.
} 


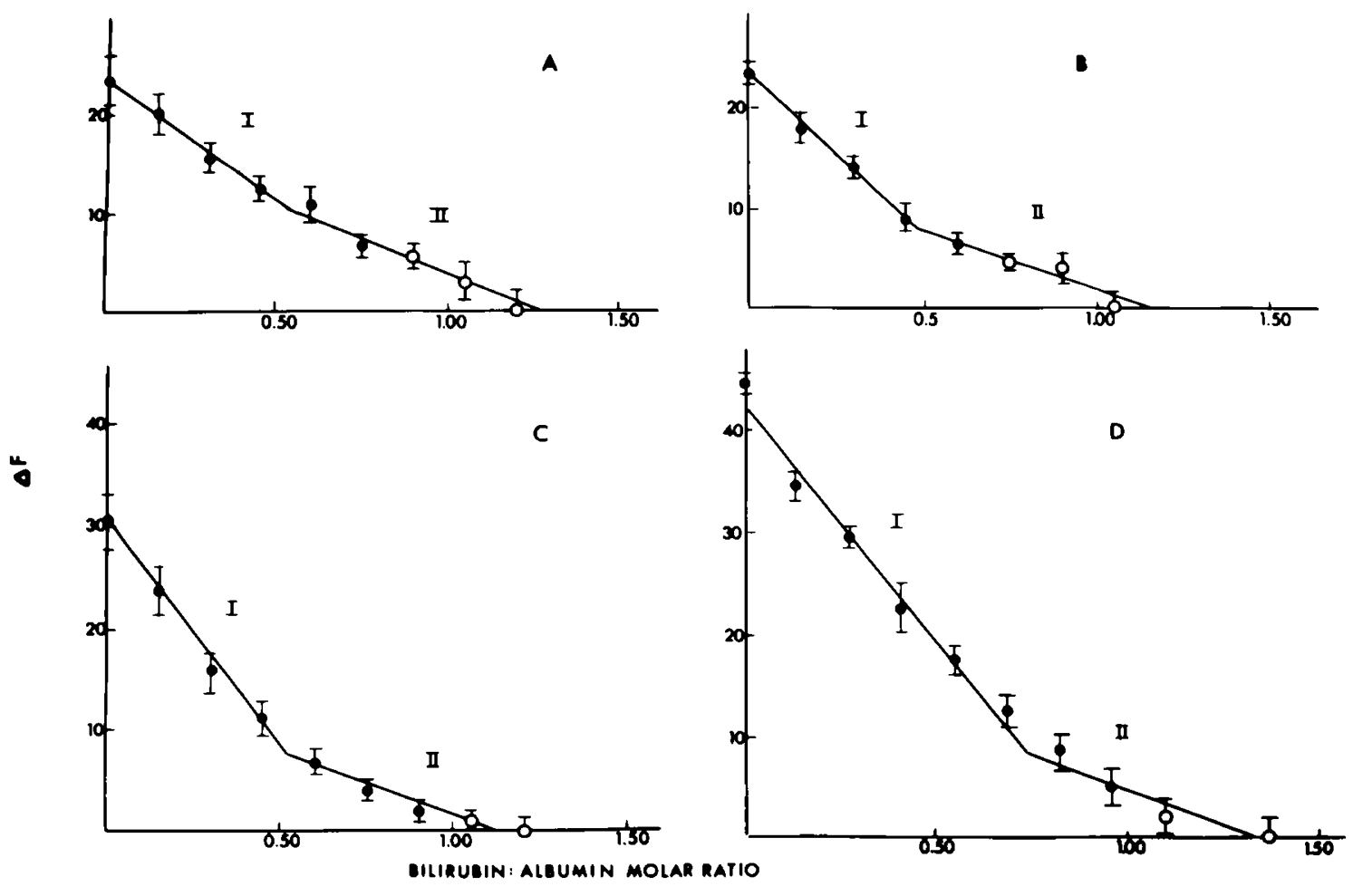

Fig. 1. Fluorescent dye binding capacity (mean $\pm \mathrm{SD} \Delta \mathrm{F}, n=4$ ) of four human serum albumin preparations with increasing bilirubin/albumin molar ratios. A: crystalline human serum albumin (Sigma), $4.0 \mathrm{~g} / \mathrm{dl}$; B: crystalline human serum albumin (Miles Lab.), $4.0 \mathrm{~g} / \mathrm{dl}$; C: liquid human serum albumin (Hyland), $4.0 \mathrm{~g} / \mathrm{dl}$; D: fresh adult human sera, albumin content, $4.4 \mathrm{~g} / \mathrm{dl}$ (data corrected to that of $4 \mathrm{~g} / \mathrm{dl}$ ). $\bullet$ : samples which gave negative Sephadex G-25 results; O positive Sephadex G-25 result. Final pH of bilirubin-albumin preparations, 7.4. Regression analysis: A, slope I $(\mathrm{y}=-24.54 \mathrm{x}+23.27, r=-0.95)$, slope II $(\mathrm{y}=-14.47 \mathrm{x}+18.24, \mathrm{r}=-0.90) ; \mathrm{B}$, slope I $(\mathrm{y}=-34.50 \mathrm{x}+24.90, r=-0.98)$, slope II $(\mathrm{y}=$ $-11.84 \mathrm{x}+13.57, r=-0.97) ; \mathrm{C}$, slope I $(\mathrm{y}=-44.80 \mathrm{x}+30.50, r=-0.98)$, slope II $(\mathrm{y}=-13.29 \mathrm{x}+14.77, r=-0.97)$; D, slope I $(\mathrm{y}=-45.28$ $+42.26, r=-0.98)$, slope II $(y=-13.61 \mathrm{x}+18.51, r=-0.97)$. Significance of $r$ for each slope of I and II for all four HSA preparations, $P<$ 0.001. Difference between slopes I and II for $\mathrm{A}, P<0.05$, and for $\mathrm{B}, \mathrm{C}$, and $\mathrm{D}, P<0.01$.

concentrations between 33 and $40 \mathrm{mg} / \mathrm{dl}$, respectively), and in fresh adult human sera, at B:A MR of 1.4 (bilirubin concentration, $50 \mathrm{mg} / \mathrm{dl}$ ).

The regression lines of $\Delta F$ in each of the four preparations resolved into two significantly different slopes $(P<0.05)$ (Fig. $1)$. The change from the first slope to the second for the purified HSA preparations (A, B, and C) occurred at B:A MR between 0.45 and 0.60 (bilirubin concentrations of 15 and $20 \mathrm{mg} / \mathrm{dl}$, respectively), whereas in fresh adult sera the change in slope occurred at 0.8 (bilirubin concentration, $26.7 \mathrm{mg} / \mathrm{dl}$ ).

All positive results obtained with Sephadex G-25 gel column chromatography (O Fig. 1) corresponded to $\Delta F$ of 5 or less and were within the second slope in all four preparations $(\mathrm{A}, \mathrm{B}, \mathrm{C}$, and D).

\section{HBABA DYE BINDINC}

This method yielded albumin binding capacities for each series as shown on Figure 2. The dye-binding capacity before addition of bilirubin was highest in fresh adult sera (preparation D) $(125.7 \pm 6.9 \%$ (SD)); lowest in crystalline HSA (Miles Lab.) (preparation B) $(83.5 \pm 4.2 \%(\mathrm{SD}))$, and intermediate in crystalline HSA (Sigma) (preparation A) and liquid HSA (Hyland) (preparation C) (Fig. 2). At a B:A MR of 1.0 , an estimated value was $85.0 \%$ in fresh adult human sera (preparation D), whereas those of purified HSA preparations were 82.0 for C, 58.0 for preparation A and 46.5 for preparation B (Fig. 2). "Apparent" HBABA binding site(s) were still available in all preparations even at bilirubin concentrations of $70 \mathrm{mg} / \mathrm{dl}$. The residual binding at $70 \mathrm{mg} / \mathrm{dl}$ ranged from $21.0 \%$ in crystalline HSA preparation B to $61.4 \%$ in fresh adult human sera (preparation D) (Fig. 2).
The HBABA values at which positive Sephadex column results $(O$, Fig. 2$)$ were first observed with increasing B:A MR also range widely; $91 \%$ in fresh sera (preparation D), $78 \%$ in liquid HSA preparation C, $63 \%$ in crystalline HSA preparation $A$, and $55 \%$ in crystalline HSA preparation B. Mean HBABA values for the points equivalent to the DY7 slope change (beginning of second slope) were $107,92,77$, and $60 \%$ for HSA preparations D, C, A, and B, respectively (Figs. 1 and 2).

\section{SATURATION INDEX}

Values for each of the four preparations (A, B, C, and D) tended to show some increase with increasing concentrations of bilirubin (Fig. 3) and values greater than 8 usually occurred with B:A MRs which exceeded 1.0 (Fig. 3). There was, however, no significant positive correlation between SI and increasing B:A MR with any of four albumin preparations $(P>0.05)$ (Fig. 3). To define the reproducibility of SI, six measurements of the same sample were performed on one series of bilirubin concentrations in HSA preparation (HSA preparation $B, 4 \mathrm{~g} / \mathrm{dl}$ ) with and without addition of sodium salicylate at bilirubin concentrations ranging from 2.5 to $70 \mathrm{mg} / \mathrm{dl}$. There was no statistically significant change in $O D$ values at $460 \mathrm{~nm}$ after addition of sodium salicylate to samples with B:A MR of 0.53 (bilirubin, $17.5 \mathrm{mg} / \mathrm{dl}$ ) or less, but there was a significant reduction for all samples with B:A MR of 0.60 (bilirubin, $20 \mathrm{mg} / \mathrm{dl}$ ) and greater $(P<0.05)$ (Fig. 4). SI values at all bilirubin concentrations throughout the range from $20-70 \mathrm{mg} / \mathrm{dl}$ were not statistically different, however (analysis of variance, $D F=5,30, F=1.95$, $P>0.05$ ) (Table 2).

SI values bore no consistent relationship to the results with Sephadex G-25 gel column chromatography DY7, or HBABA. 

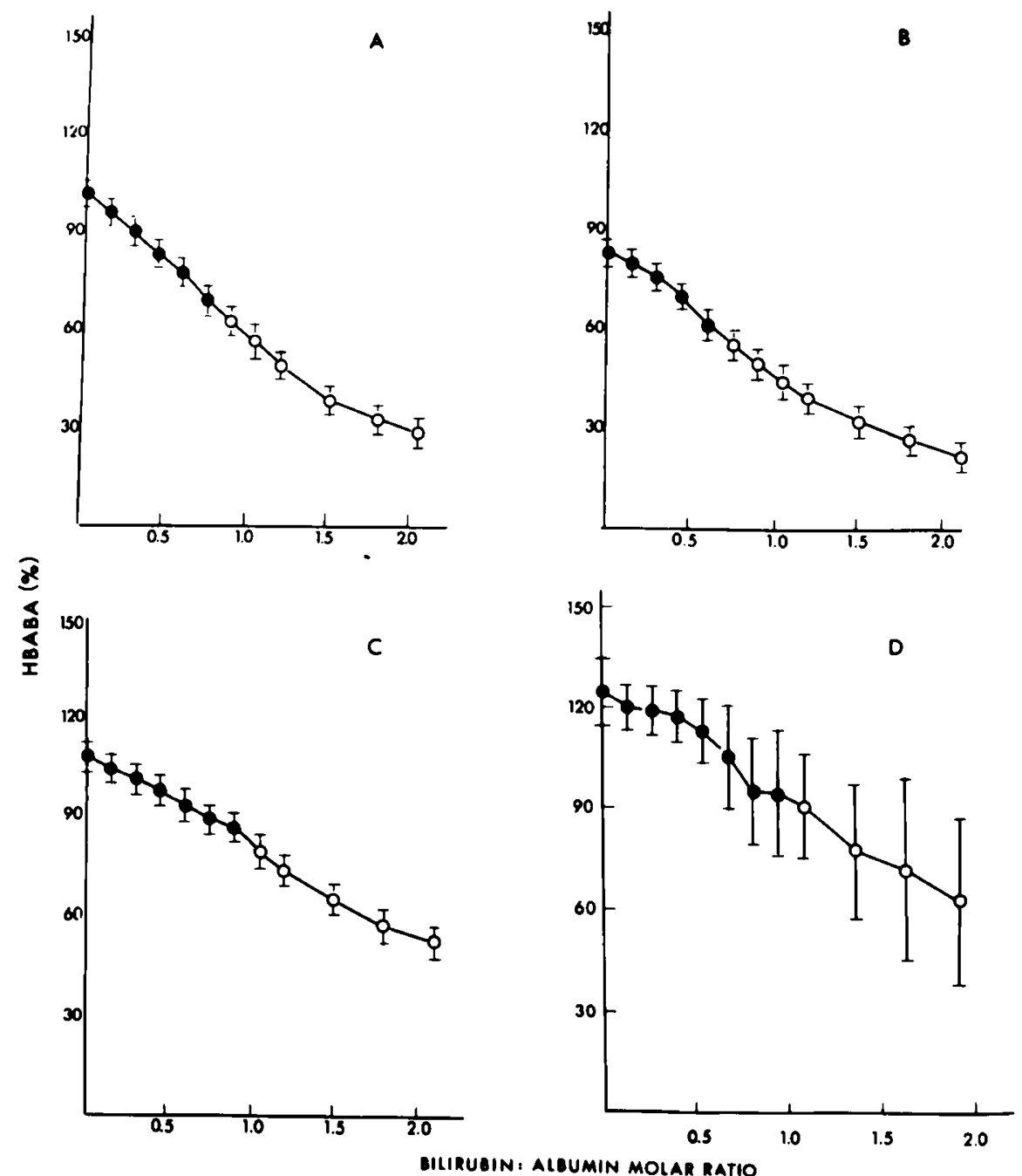

Fig. 2. HBABA dye binding capacity (percentage of mean $\pm S D \%, n=4$ ) of four human serum albumin preparations with increasing bilirubin/ albumin molar ratios. A, B, C, and D are the same as in Figure 1. Symbols are $\bullet$ and $O$ as in Figure 1.

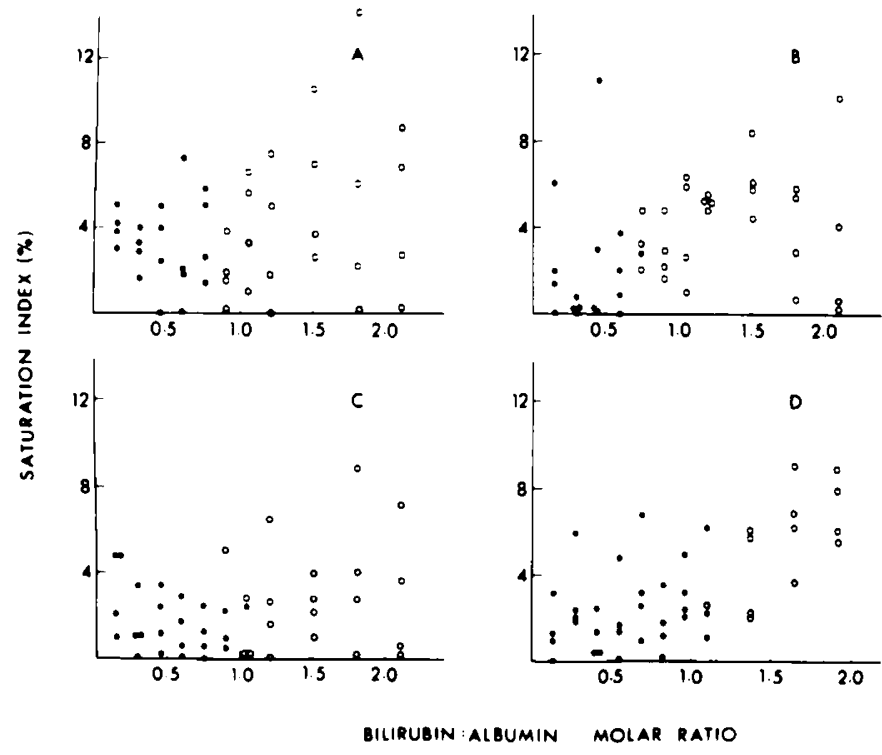

Fig. 3. Saturation index (percentage) values of four human serum albumin preparations $(n=4$ each) with an increasing bilirubin/albumin molar ratio. A, B, C, and D are the same as in Figure 1. $O$ and $O$ as in Figure 1.

\section{DISCUSSION}

The present study demonstrates the diversity in results of the measurement of albumin binding capacity for bilirubin (or reserve albumin binding capacity) in identical specimens using four different methods.

\section{SEPHADEX G-25 COLUMN CHROMATOGRAPHY}

This method is based on competitive binding of bilirubin by the gel (9). Bilirubin not bound or "loosely" bound to albumin is believed to remain on column after elution of the proteins. The bilirubin left in column is either qualitatively measured by diazo reaction (11), or quantitatively measured as "free bilirubin" by elution followed by chemical or direct spectrophotometric techniques (2). The reddish purple staining of the gel column by a diazo reaction or an amount of "free bilirubin" $0.1 \mathrm{mg} / \mathrm{dl}$ or above has been reported to be associated with a risk for the development of kernicterus (11).

The present study with Sephadex G-25 column chromatography confirms previous studies demonstrates that fresh adult human sera binds one mole of bilirubin tightly; exceeding this B:A MR, bilirubin begins to adsorb to the gel (10). The binding capacity of purified HSA preparations was variably deficient compared to that of adult human sera, supporting a similar result obtained previously with the fluorescent dye binding method (15). 


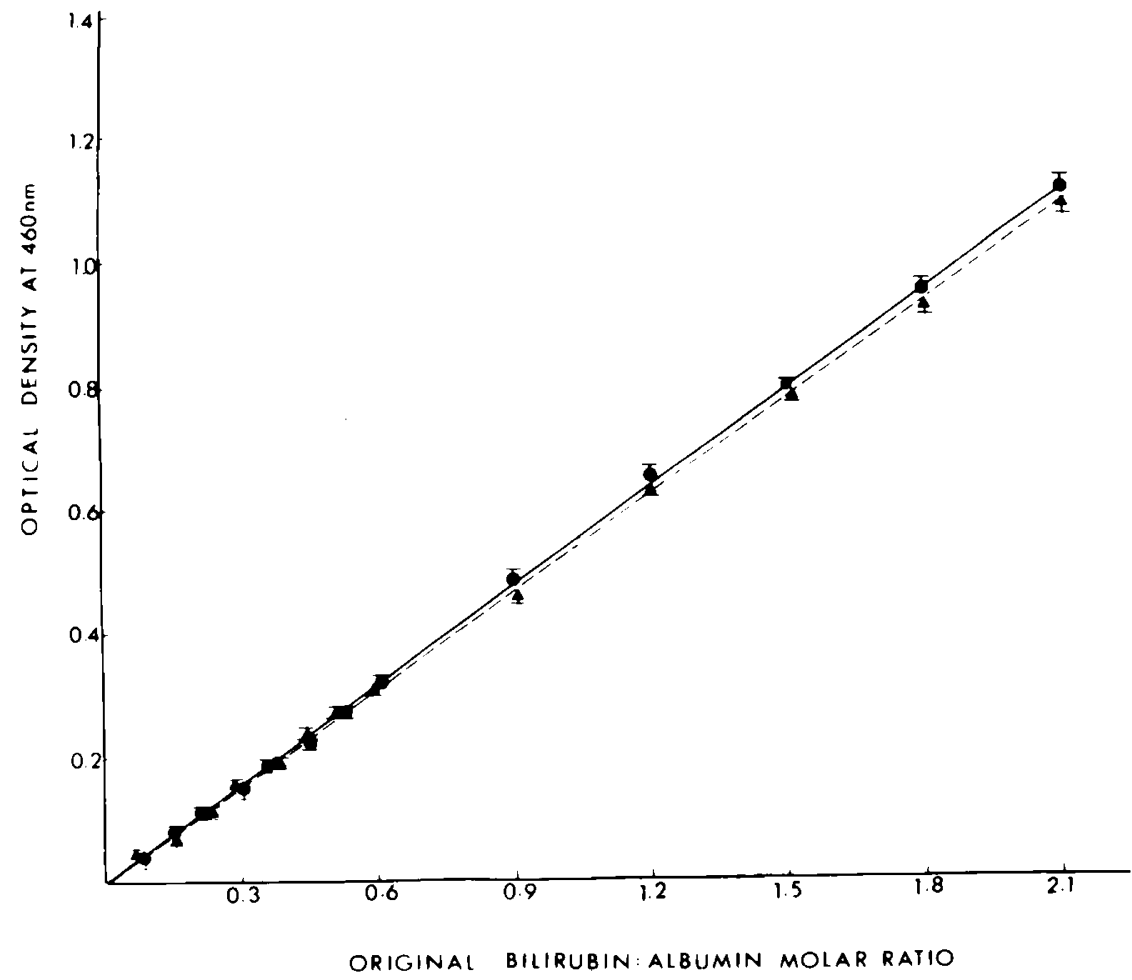

Fig. 4. Optical density values (mean $\pm \mathrm{SD}, n=6$ each) of bilirubin (milligrams/dl) in human serum albumin (Miles Lab.) solution (4 $\mathrm{g} / \mathrm{dl}, 0.1 \mathrm{M}$ phosphate buffer, $\mathrm{pH} 7.4$ ) before $(\bullet)$ and after $(\Delta)$ addition of sodium salicylate according to the method of Odel $e t$ al. (8).

Table 2. Saturation index values of bilirubin-human serum albumin (Miles Lab.) preparations (albumin, $4 \mathrm{~g} / \mathrm{dl}$, in $0.1 \mathrm{M}$ phosphate buffer, $\mathrm{pH} 7.4$ )

\begin{tabular}{cccc}
$\begin{array}{c}\text { Biliru- } \\
\text { bin, mg/ } \\
\text { dl }\end{array}$ & B:A MR & SI $^{2}$ & Difference $^{3}$ \\
\hline 20 & 0.6 & $1.9 \pm 1.3$ & \\
30 & 0.9 & $2.3 \pm 1.7$ & \\
40 & 1.2 & $3.7 \pm 1.7$ & F $=1.95$ \\
50 & 1.5 & $4.5 \pm 1.7$ & (DF: 5, 30) \\
60 & 1.8 & $3.1 \pm 1.7$ & $P>0.05$ \\
70 & 2.1 & $3.7 \pm 1.9$ & \\
\hline
\end{tabular}

${ }^{1}$ Bilirubin/albumin molar ratio.

${ }^{2}$ Mean \pm SD, number of samples at each bilirubin concentration, $n=6$.

${ }^{3}$ Analysis of variance.

\section{FLUORESCENT DYE BINDING}

This method is based on competitive binding to albumin of DY7 and bilirubin (15). The dye appears to bind only to bilirubin-binding sites on albumin (15) to produce enhanced fluorescence. Thus, the extinction of the enhanced fluorescence $(\Delta \mathrm{F})$ occurred in adult sera and all HSA preparations in the presence of increasing bilirubin concentrations, signifying the complete inhibition of dye binding at the bilirubin-binding sites on albumin. The DY7 inhibition curves for adult sera and all purified HSA preparations demonstrated two distinct regression lines in the presence of increasing bilirubin concentrations. The change in slope may represent a shift from the first to the second binding site for bilirubin on albumin (15) due to a change in relative binding affinities for the two sites. Although the estimated binding capacity of the second site appears not to be different among the four preparations studied (slope and intercept), the binding capacity of first site appears greater in adult sera than that of the purified HSA preparations, confirming the previous DY7 study (15).
It should be noted that the change in slope for fresh adult sera in the original report of this method (15) occurred at B:A MR of 1.0 whereas in the present report this change occurs at 0.8 . This difference results both from a change in the method for measurement of albumin concentration and to the naturally occurring variation between individuals. In the original report agarose gel electrophoresis was used to determine albumin concentration, whereas in the present study bromcresol green was used.

\section{HBABA DYE BINDING}

This method is based on competitive binding to albumin of the HBABA dye and bilirubin (19). Less than 25-30\% residual binding capacity has been believed to be associated with a risk for the development of kernicterus $(20,24)$. In the present study, HBABA dye binding was not completely prevented even at the highest bilirubin concentrations studied $(70 \mathrm{mg} / \mathrm{dl}, \mathrm{B}: \mathrm{A}$ MR of 2) leaving 20-50\% apparent residual binding capacity in each of the four different preparations studied. HBABA dye has been shown to share albumin binding site(s) with various antimicrobial agents, including penicillin and tetracycline preparations (16), which have not been shown to compete with bilirubin for albumin binding by other methods (23). It appears that the measurement of HBABA dye-binding capacity is not specific for bilirubin binding to albumin as it involves additional non-bilirubin binding sites of albumin.

\section{SATURATION INDEX}

This method is based on the concept that the reduction of optical density at $460 \mathrm{~nm}$ in icteric sera after the addition of sodium salicylate is due to the displacement of bilirubin from original binding site(s) on albumin (17). It is an estimate of the proportion of bilirubin which is displacable.

The present study demonstrated that SI values of the samples with $B: A$ MR above 1 tend to be higher than those with B:A MR below 1 . Individual SI values, however, varied widely throughout the range of $B: A$ MR. The difficulty with this 
method was in obtaining a precise OD value of the sample. The maximum reduction in OD after the addition of sodium salicylate is approximately $14 \%$ of the original OD $(17,22)$. The reduction of $8 \%$ or more thas been reported to be associated with a risk for development of kernicterus (18). In our study, the mean random variation of OD value in the same sample was approximately $\pm 4 \%$ regardless of the presence or absence of salicylate. The lack of significant change in SI values when bilirubin concentrations were $17.5 \% \mathrm{mg} / \mathrm{dl}$ or less may thus be attributable to this random variation.

At bilirubin concentrations of $20 \mathrm{mg} / \mathrm{dl}$ or higher, there was a statistically significant reduction in OD at $460 \mathrm{~nm}$ (hence, increased SI) after addition of sodium salicylate. The observed progressive increase in SI value, as expected (Table 2), was not significant, however, because of the large standard deviation resulting from large random variations in $O D$ as mentioned above. These findings confirm a similar conclusion drawn by others $(1,22)$ that the SI method is not precise enough for the determination of the saturation of albumin by bilirubin.

\section{COMPARISON OF FOUR METHODS}

There have been several studies $(1,5,20)$ comparing methods for the measurement of bilirubin-albumin binding. Priolisi and Ziino (20) demonstrated a good correlation between the SI and HBABA values. However, the measurement was made on a single sample for each B:A MR. Frenzel et al (5) found no correlation between the amount of unbound bilirubin ("free bilirubin") measured with Sephadex gel column and HBABA value in jaundiced newborn sera. Bratlid (1) determined binding capacity of 105 jaundiced newborn sera with three methods, the red cell binding of bilirubin, HBABA dye binding, and SI method. He found that the result of red blood cell binding correlated with B:A MR of the samples but neither the SI nor the HBABA value did. He did not give a correlative data on the values between $\mathrm{SI}$ and HBABA.

In our present study, Sephadex G-25 gel column chromatography, DY7 fluorescent dye binding, and HBABA dye binding concur in demonstrating that fresh adult human sera has a higher molar binding capacity than either of the three purified HSA preparations. The DY7 fluorescent dye binding method and Sephadex G-25 gel column chromatography were in close agreement in defining a critical point at which bilirubin binding to albumin is presumably insufficient. The clear detection of bilirubin adsorbed to the Sephadex gel coincides with a reduction in residual binding capacity to $12 \%$ or less of that of fresh adult sera. This is equivalent to a DY7 $\triangle A$ value of 5 or less in all four HSA preparations. These $\Delta F$ values are all on the second slope and are presumed to represent binding of bilirubin on the second or weaker binding site.

HBABA values ranged widely from one HSA to another and in relation to either the $\Delta F$ values corresponding to the beginning of the second slope or the lowest $B: A$ MR which yielded a positive Sephadex test. HBABA values ranged from $104 \%$ to $60 \%$ for those points corresponding to $\Delta F$ values of 5 to 0 and from $91 \%$ to $55 \%$ for those points corresponding to initial Sephadex column positivity. The rank order of HBABA binding capacity among the four HSA preparations parallels the original HBABA binding capacities in these preparations before addition of bilirubin. This finding suggests that there may be significant differences in available non-billirubin-binding sites on albumin for HBABA between adult sera and each of the various purified HSA preparations. This interpretation is further supported by the previous work of Chan et al. (2). In their study, the "free" or loosely bound bilirubin measured with Sephadex G-25 gel column chromatography was not recovered until the concentration of oleate exceeded $1.5 \mathrm{mEq} / \mathrm{liter}$. At this oleate concentration there was already a $40-50 \%$ depression of reserve albumin binding capacity measured with the HBABA dye binding method. This suggests that a significant cause of varia- bility in HBABA values in newborns may also relate to differences in non-bilirubin binding site capacities.

In our study, SI value had no consistent relationship to the binding results obtained with the other three methods. The diversity in results of albumin binding of bilirubin measured with different methods on both purified human serum albumin preparations and fresh adult human sera suggests that each of these methods may be measuring a somewhat different aspect of bilirubin binding to albumin. The variability in binding results obtained with different albumin preparations and their significant difference from results obtained with fresh adult sera suggest that future studies of binding methods might best be studied first and standardized with fresh adult sera.

\section{CONCLUSION}

Three methods, fluorescent dye binding, Sephadex G-25 column chromatography, and HBABA dye binding, demonstrated that fresh adult human sera had a higher molar albumin binding capacity for bilirubin than the purified human serum albumin preparations. The fluorescent dye binding and Sephadex gel column methods appear to yield relatively consistent results and probably measure bilirubin-albumin binding with some specificity. The HBABA method suffers from less specificity and the SI method, at least in our hands, yields inconsistent results because of a high ratio of laboratory error relative to expected small changes in optical density.

\section{REFERENCES AND NOTES}

1. Bratlid, D.: Reserve albumin binding capacity, salicylate index, and red cell binding of bilirubin in neonatal jaundice. Arch. Dis. Childhood, 48: 393 (1973).

2. Chan, G., Schiff, D., and Stern, L.: Competitive binding of free fatty acids and bilirubin to albumin: Difference in results. Clin. Biochem., 4: 208 (1971).

3. Diamond, I., and Schmid, R.: Experimental bilirubin encephalopathy: The mode of entry of bilirubin- ${ }^{14} \mathrm{C}$ into the central nervous system. J. Clin. Invest., 45: 678 (1966).

4. Doumas, B. T., and Biggs, H. G.: Determination of serum albumin. In: G. R. Cooper: Standard Methods of Clinical Chemistry, Vol. 7, pp. 175-188 (Academic Press, New York, 1972).

5. Frenzel, J., Sander, I., and Schramm, D.: Comparative analysis between albumin binding capacity and concentration of unbound bilirubin in hyperbilirubinemia sera of newborn infants. Z. Kinderheilk., 115: 187 (1973).

6. Goldstein, A.: Biostatistics: An Introductory Text. pp. 51, 70, 129 (The Macmillan Co., New York, 1964).

7. Jacobsen, J., and Fedders, O.: Determination of non-albumin-bound bilirubin in human serum. Scand. J. Clin. Lab. Invest., 26: 237 (1970).

8. Jendrassik, L., and Grof, P.: Vereinfachte photometrische Methoden zur Bestimmung des Blut-Bilirubins. Biochem. Z., 297: 81 (1939).

9. Jirsova, V., Jirsa, M., Heringova, A., Koldovsky, O., and Weirichova, J.: The use and possible diagnostic significance of Sephadex gel filtration of serum from icteric newborns. Biol. Neonate, 11: 204 (1967).

10. Kapitulnik, J., Blondheim, S. H., and Kaufmann, N. A.: Sephadex absorption of bilirubin from neonatal and adult serum. Clin. Chem., 18: 43 (1972).

11. Kapitulnik, J., Valaes, T., Kaufmann, N. A., and Blondheim, S. H.: Clinical evaluation of Sephadex gel filtration in estimation of bilirubin binding in serum in neonatal jaundice. Arch. Dis. Childhood, 49: 886 (1974).

12. Kaufmann, N. A.. Simcha, A. J., and Blondheim, S. H.: The uptake of bilirubin by blood cells from plasma and its relationship to the criteria for exchange transfusion. Clin. Sci., 33: 201 (1967).

13. Klatskin, G., and Bungards, L.: Bilirubin-protein linkage in serum and their relationship to the Van den Berg reaction. J. Clin. Invest., 35: 537 (1956).

14. Krasner, J., Giacoia, G. P., and Yaffe, S. J.: Drug-protein binding in the newborn infant. Ann. N. Y. Acad. Sci., 226: 101 (1973).

15. Lee, K. S., Gartner, L. M., and Zarafu, I.: Fluorescent dye method for determination of the bilirubin-binding capacity of serum albumin. J. Pediat. 86: 280 (1975)

16. Malaka-Zafiriu, K., and Strates, B. S.: The effect of antimicrobial agents on the binding of bilirubin by albumin. Acta Paediat. Scand., 58: 218 (1969).

17. Odell, G. B., Cohen, S. N., and Kelly, P. C.: Studies in kemicterus. II. The determination of the saturation of serum albumin with bilirubin. J. Pediat., 74: 214 (1969)

18. Odell, G. B., Storey, G. N. B., and Rosenberg, L. A.: Studies in kernicterus. III. The saturation of serum proteins with bilirubin during the neonatal life and its relationship to brain damage at five years. J. Pediat., 76: 12 (1970).

19. Porter, E. G., and Waters, W. J.: A rapid micro method for measuring reserve albumin binding capacity in serum from newborn infants with 
hyperbilirubinemia. J. Lab. Clin. Med.. 67: 660 (1966).

20. Priolisi, A., and Ziino, L.: The comparative analysis between the reserve albumin-binding capacity (HBABA method) and saturation index of hyperbilirubinemic sera. Biol. Neonate, 19: 258 (1971).

21. Ostrow, J. D., and Schmid, R.: The protein-binding of $\mathrm{C}^{14}$ bilirubin in human and murine serum. J. Clin. Invest., 42: $1286(1963)$

22. Seem, E., and Wille, L.: Salicylate saturation index in neonatal jaundice. Biol. Neonate, 26: 67 (1975).

23. Stern, L.: Drug interactions. II. Drugs, the newborn infant, and binding of bilirubin to albumin. Pediatrics, 35: 482 (1972).

24. Svenningsen, N. W., and Lindquist, A.: HBABA index in neonatal jaundice. In: Proceedings of the XIIth International Congress of Pediatrics, Vienna, Vol. 1, p. 305,1971

25. Woolley, P. V., III, and Hunter, M. J.: Binding and circular dichroism data on bilirubin-albumin in the presence of oleate and salicylate. Arch. Biochem. Biophys., 140: 197 (1970).
26. Dr. Lee is a Clinical Investigator Awardee from the NIAMDD (1KO8 AM00219-01).

27. Dr. Gartner is a Career Development Awardee from the NICHHD (5KO3 HD23073).

28. Dr. Vaisman was a recipient of an International Fellowship from the NIH (5FO5 TW01850).

29. A portion of this work was presented at the Annual Meeting of the Society for Pediatric Research, St. Louis, April 1976.

30. This work has been supported by Grant 5RO1 HDO3783 from the NICHHD and by a grant from the Gail I. Zuckerman Foundation for Research in Chronic Liver Diseases of Children.

31. Requests for reprints should be addressed to: Kwang-sun Lee, M.D., The Rose F. Kennedy Center, Albert Einstein College of Medicine, Bronx, NY 10461 (USA).

32. Received for publication March 23, 1977

33. Accepted for publication July 27, 1977. 